\title{
Classificação dos linfomas não-Hodgkin: estudo morfológico e imunoistoquímico de 145 casos
}

\author{
Classification of non-Hodgkin's lymphoma: morphological and immunological study of 145 cases
}

\author{
Cristiane Bedran Milito ${ }^{1}$ \\ José Carlos Morais ${ }^{1}$ \\ Márcio Nucci² \\ Wolmar Pulcheri² \\ Nelson Spector ${ }^{2}$
}

\section{unitermos resumo}

Linfoma não-Hodgkin

Classificação
A classificação dos linfomas não-Hodgkin tem sido, ao longo dos últimos trinta anos, motivo de controvérsia. Várias classificações têm sido propostas em busca de um consenso entre patologistas e clínicos. Este trabalho teve como objetivo analisar criticamente três destas classificações através do estudo retrospectivo de 145 casos de linfomas primários de gânglio linfático selecionados do Serviço de Anatomia Patológica do Hospital Universitário Clementino Fraga Filho, entre 1979 e 1995. Os casos revistos foram classificados pelas propostas da Working Formulation, de Kiel e da Real. Testes imunoistoquímicos com os anticorpos anti-CD45, anti-CD20, anti-CD45RO e anti-CD30 foram realizados. Cento e sete casos (73,7\%) apresentaram fenótipo B; 33 casos (22,7\%), fenótipo T; e quatro casos foram nulos (linfoma anaplásico de grandes células). Foi possível prever o fenótipo pela morfologia em 89,4\% dos casos. Os linfomas de alto grau predominaram $(59,2 \%)$, sendo o linfoma centroblástico o de maior freqüência (31,7\% ). Os linfomas foliculares representaram 29 casos (20\%), com maior incidência dos de grandes células (31\%) do que dos de pequenas células (27,5\%). Quando comparadas as três classificações, observamos que determinados grupos da Working Formulation abrigam múltiplas entidades. Isto se deve ao fato de a classificação da Working Formulation ser baseada somente em achados morfológicos e, por isso, deve ter seu uso desaconselhado. Já a classificação de Kiel e a da Real devem ter o seu emprego estimulado, pois apresentam, além de uma boa análise histopatológica, um estudo imunológico que define entidades biológicas correlacionando-se, quando possível, com a célula de origem. 


\section{Introdução}

Até meados da década de 70 havia consenso entre os patologistas que utilizavam rotineiramente a classificação de Rappaport $(33,34)$. Entretanto, com o reconhecimento de que o linfócito não é uma célula terminal, e, sim, uma célula em repouso, aguardando um estímulo antigênico para ser ativada, caiu o conceito da diferenciação linfocitária e, com ele, a classificação de Rappaport. A descoberta das subpopulações linfocitárias fez com que outras classificações fossem propostas. Lukes e Collins (22), nos Estados Unidos, e Lennert (17), na Alemanha, quase que simultaneamente e à luz destes novos conhecimentos, fizeram as suas propostas de classificação. Em 1982, em trabalho patrocinado pelo National Cancer Institute, um grupo de hematopatologistas analisou, em um estudo retrospectivo, mais de mil casos de LNH em que foram aplicadas as seis classificações existentes. Além de concluírem que todas as classificações estudadas eram válidas e que apresentavam boa correlação clinicopatológica, os autores propuseram uma nova terminologia que serviria de tradutor entre as classificações. O objetivo era criar uma linguagem universal, para tornar possível a comparação das experiências entre instituições de todos os países. $\mathrm{O}$ próprio nome sugeria isto: Working Formulation for Clinical Usage (35). Infelizmente, o resultado deste trabalho foi a adoção da proposta com uma nova classificação, que se difundiu amplamente pela América do Norte. No final da década de 80, Lennert (39) publicou a sua classificação revisada, incorporando novos subtipos de LNH. Recentemente, um grupo de dezenove especialistas, predominantemente europeus e americanos, não-envolvidos com as classificações anteriores, resolveu submeter à comunidade científica uma proposta que, ao invés de classificação, é chamada de listagem de entidades e sugestivamente denominada Real (Revised European-American Classification of Lymphoid Neoplasms), incorporando todas as doenças linfoproliferativas (9).

Em 1995, a OMS adotou a classificação Real com o objetivo de revisá-la e atualizá-la. Era uma nova tentativa de consenso para tornar padrão esta nova classificação $(10,13)$.

O objetivo deste trabalho foi estudar os casos de LNH primários de gânglios linfáticos, no Hospital Clementino Fraga Filho (HCFF), da Universidade Federal do Rio de Janeiro (UFRJ), no período de janeiro de 1979 a dezembro de 1995. Revimos os casos de LNH, empregamos e analisamos criticamente as classificações da Working Formulation, de Kiel modificada e da Real, procuramos identificar as entidades clinicopatológicas e correlacionamos a morfologia com o fenótipo.

\section{Material e métodos}

Dos 228 casos catalogados, foram selecionados para estudo os 145 em que havia disponibilidade dos blocos de parafina.

$\mathrm{Na}$ análise histopatológica, foram examinados preparados histológicos representativos de biópsias de gânglios linfáticos, corados pela hematoxilina-eosina (HE). Quando necessário, foram solicitadas colorações especiais de PAS (periodic acid schiff), May Grünwald-Giemsa e reticulina de Gomori.

Testes imunoistoquímicos, em blocos de parafina, utilizando os anticorpos monoclonais anti-CD20 e anti-CD45RO (UCHL1), foram realizados em todos os 145 casos. O anticorpo anti-CD45 (LCA) foi utilizado quando havia dúvida no diagnóstico de neoplasia linfóide, e o anti-CD30 (BerH2), para confirmar o diagnóstico de linfoma anaplásico.

A origem e diluição dos anticorpos foi a seguinte: antiCD20, soro de camundongo, clone L26, monoclonal (Dako) na diluição de 1:100; anti-CD45RO, soro de camundongo, clone UCHL1, monoclonal (Dako) na diluição de 1:50; anti-CD3, soro de coelho, policlonal (Dako) na diluição de 1:100, anti-CD45 (LCA), soro de camundongo, clone T29/33, monoclonal na diluição de 1:100; antiCD30, soro de camundongo, clone BerH2, monoclonal (Dako) na diluição de 1:10.

Os cortes histológicos foram desparafinizados em xilol a $60^{\circ} \mathrm{C}$ por 30 minutos e, posteriormente, em temperatura ambiente, por 20 minutos. Foram hidratados em soluções alcoólicas e água. As lâminas foram incubadas em solução de ácido cítrico 0,01M com pH 6 em duas etapas de cinco minutos, no forno de microondas (700W), visando à recuperação antigênica. A atividade da peroxidase endógena foi bloqueada com solução de peróxido de hidrogênio a $3 \%$ em metanol, por 30 minutos. Os cortes histológicos foram incubados com anticorpos primários em câmara úmida a $40^{\circ} \mathrm{C}$ por 18 horas. Seguiu-se a incubação do anticorpo secundário Duet (camundongo/coelho), conjugado com biotina, IgG de cabra anticamundongo e anticoelho, em câmara úmida, a $37^{\circ} \mathrm{C}$, por 30 minutos. Entre as incubações foram feitas lavagens em tampão PBS (phosphate buffered solution), $\mathrm{pH}$ 7,4 . A reação foi detectada através da incubação com o sistema estreptoavidina-biotina-peroxidase (Strep $A B$ 
complex/HRP, Duet Mouse/Rabbit, Dako S/A Dinamarca), na diluição de 1:500. A revelação deu-se com substrato cromógeno (DAB líquido: 40 microlitros para $1 \mathrm{ml}$ de tampão substrato Dako - K3465), por cinco minutos, a $37^{\circ} \mathrm{C}$. Os cortes foram contracorados com a hematoxilina de Harris.

Os casos de LNH foram revisados e classificados de acordo com as classificações de Kiel modificada (1988) (39), da Real (1994) (9) e da Working Formulation (35).

\section{Resultados}

Cento e quarenta e cinco casos de LNH foram revistos, empregando-se as classificações de Kiel modificada, a Real e a Working Formulation.

Os resultados pela Working Formulation são observados na Tabela 1. Para a análise das outras classificações, foi necessário o resultado da imunofenotipagem, baseada na positividade das células neoplásicas para os anticorpos anti-CD20 e anti CD-45RO (Figuras 1 e 2). Apresentaram fenótipo B 107 casos (74\%) e fenótipo T, 33 casos (23\%). Quatro casos, diagnosticados como linfoma anaplásico de grandes células, foram negativos para os marcadores $B$ e
T. Um dos casos inclassificáveis marcou para B e o outro foi negativo para $B, T$ e CD30.

A Tabela 2 demonstra os resultados pela classificação de Kiel e a Tabela 3, pela Real.

Fizemos em seguida o cruzamento de alguns subtipos da Working Formulation: linfoma misto difuso (F), de grandes células $(G)$, difuso de células pequenas clivadas (E) com as entidades representadas na classificação de Kiel e na Real (Tabelas 4, 5 e 6).

\section{Discussão}

Algumas classificações têm como base os achados histopatológicos, ao contrário de outras, em que a imunofenotipagem é essencial. Pertence ao primeiro grupo a Working Formulation (35), que deve ter o seu uso desaconselhado por ser fundamentada em aspectos puramente morfológicos e abrigar, em alguns grupos, múltiplas entidades. Um exemplo disto é a categoria do linfoma misto difuso $(1,18,19,36)$. Em nosso material, também observamos esta heterogeneidade: o linfoma misto difuso, quando enquadrado na classificação de Kiel, apareceu como linfoma linfoepitelióide, linfoma de zona T, linfoma

\section{Tabela 1 Resultado pela classificação da Working Formulation}

\begin{tabular}{|c|c|c|}
\hline & Número & $\%$ \\
\hline \multicolumn{3}{|l|}{ Baixo grau } \\
\hline A - Linfoma maligno (LM) linfocítico & 8 & 5,5 \\
\hline $\begin{array}{l}\text { B - LM folicular } \\
\text { Predomínio de pequenas células clivadas }\end{array}$ & 8 & 5,5 \\
\hline $\begin{array}{l}\text { C - LM folicular } \\
\text { Misto: pequenas e grandes células }\end{array}$ & 12 & 8,3 \\
\hline \multicolumn{3}{|l|}{ Grau intermediário } \\
\hline $\begin{array}{l}\text { D - LM folicular } \\
\text { Predomínio de grandes células }\end{array}$ & 9 & 6,2 \\
\hline $\begin{array}{l}\text { E - LM difuso } \\
\text { Pequenas células clivadas }\end{array}$ & 13 & 9 \\
\hline $\begin{array}{l}\text { F - LM difuso } \\
\text { Misto: pequenas e grandes células }\end{array}$ & 23 & 15,9 \\
\hline $\begin{array}{l}\text { G - LM difuso } \\
\text { Grandes células }\end{array}$ & 52 & 35,9 \\
\hline \multicolumn{3}{|l|}{ Alto grau } \\
\hline H - LM de grandes células - imunoblástico & 3 & 2,1 \\
\hline I - LM linfoblástico & 6 & 4,1 \\
\hline J - LM de células não-clivadas Burkitt & 9 & 6,2 \\
\hline $\begin{array}{l}\text { K - Miscelânea (compósito, micose fungóide, histiocítico, } \\
\text { plasmocitoma extramedular e inclassificável) }\end{array}$ & 2 & 1,4 \\
\hline
\end{tabular}




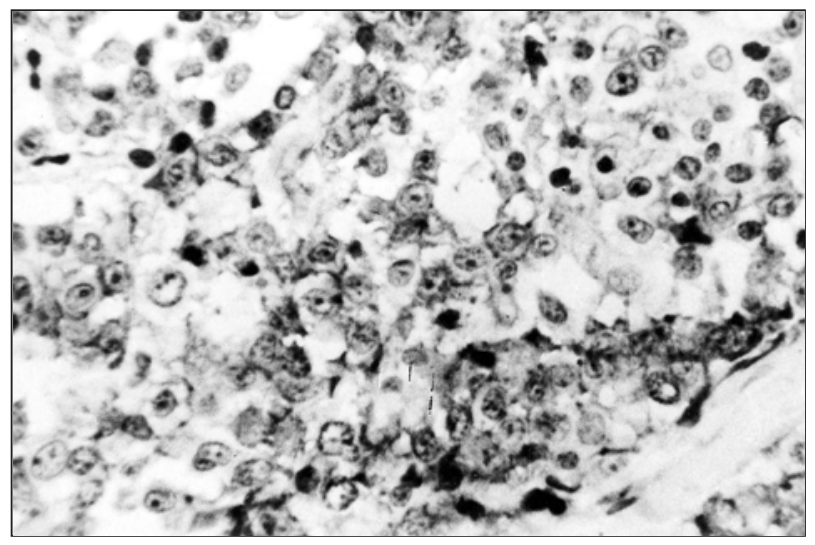

Figura 1 - Linfoma difuso de grandes células: presença de imunorreatividade de membrana celular com o anticorpo anti-CD20

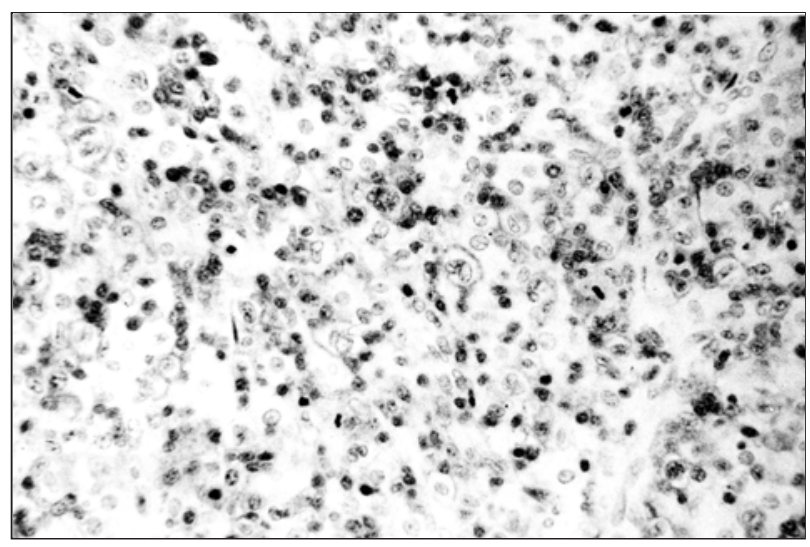

Figura 2 - Linfoma T periférico: imunopositividade de membrana celular com 0 anticorpo anti-CD45RO

pleomórfico de pequenas células, imunocitoma e linfoma pleomórfico de médias e grandes células. Ao empregarmos a classificação Real, este linfoma correspondia a ca- sos de imunocitoma, linfoma T periférico e LLTA (Tabela 4). Da mesma forma, o linfoma difuso de pequenas células engloba várias entidades. Na classificação de Kiel: linfoma monocitóide, linfoma da zona do manto e linfoma pleomórfico de pequenas células; na classificação Real: linfoma de células do manto, linfoma monocitóide e linfoma T periférico (Tabela 6). Já o linfoma de grandes células corresponde, na classificação de Kiel, a linfoma centroblástico e linfoma anaplásico de grandes células, e, na classificação Real, a linfoma de grandes células, linfoma anaplásico de grandes células e linfoma de grandes células B com esclerose do mediastino (Tabela 5). Outra limitação da Working Formulation é não incluir a análise imunofenotípica. Por este motivo, alguns subtipos de linfomas deixaram de ser identificados, como, por exemplo, os LNH T, cujos aspectos histopatológicos estão bem descritos na literatura $(27,32,42)$.

A Working Formulation permitiu subdividir os LNH de acordo com os grupos prognósticos que apresentavam importância clínica $(29,35,38)$. Esta foi sua grande contribuição. Os LNH foram divididos em três categorias: baixo, intermediário e alto grau, de acordo com as curvas de sobrevida. No trabalho original, realizado pelo National Cancer Institute em 1982, foram estudados 1.153 pacientes. Em nossa casuística, observamos 19,3\% (28 casos) de baixo grau, 67\% (97 casos) de grau intermediário e 12,4\% (18 casos) de alto grau. Nossos achados se aproximam mais dos de Lieberman et al. (19) (1986), que encontraram 142 (29\%) casos de LNH de baixo grau, 257 (54\%) de grau intermediário e 57 (12\%) de alto grau. Mesmo assim, nossa incidência de linfomas de baixo grau é me-

\section{Tabela 2 Resultado pela classificação de Kiel modificada}

\begin{tabular}{|c|c|c|c|}
\hline Linfomas B & Número $(\%)$ & Linfomas T & Número $(\%)$ \\
\hline Linfocítico & $8(5,5)$ & & \\
\hline Linfoplasmacítico/-citóide & $2(1,4)$ & Linfoepitelióide & $1(0,7)$ \\
\hline Centrobl. centrocítico & $29(20)$ & Linfoma da zona T & $2(1,4)$ \\
\hline Centrocítico (manto) & $8(5,5)$ & Pleomórfico de pequenas células & $5(3,4)$ \\
\hline Monocitóide (marginal) & $2(1,4)$ & & \\
\hline Centroblástico & $46(31,7)$ & Pleomórfico de médias e grandes células & $16(11)$ \\
\hline Imunoblástico & $1(0,7)$ & Imunoblástico & $2(1,4)$ \\
\hline \multirow[t]{3}{*}{ Linfoma de Burkitt } & $9(6,2)$ & & \\
\hline & & Anaplásico de grandes células & $2(1,4)$ \\
\hline & & Linfoblástico & $2(1,4)$ \\
\hline Anaplásico de grandes células (nulo) & $4(2,7)$ & & \\
\hline Inclassificáveis & $2(1,4)$ & & \\
\hline
\end{tabular}




\section{Tabela 3 Resultado pela classificação Real}

\begin{tabular}{lcc}
\hline & Número & $\%$ \\
Neoplasias de células B periféricas & & 5,5 \\
\hline Linfoma linfocítico de células pequenas & 8 & 1,4 \\
Linfoma linfoplasmocitóide, imunocitoma & 2 & 5,5 \\
Linfoma da célula do manto & 8 & 20 \\
Linfoma do centro do folículo, folicular & 29 & 1,4 \\
Linfoma de zona marginal & 2 & 29,7 \\
Linfoma difuso de grandes células & 43 & 2,8 \\
$\quad$ Subtipo: linfoma primário do mediastino & 4 & 6,2 \\
Linfoma de Burkitt & 9 & \\
& & 4,1 \\
Neoplasia de células T precursoras & 6 & \\
Leucemia/linfoma linfoblástico & & 13,8 \\
Neoplasias de células T periféricas & & 4,1 \\
\hline Linfoma T periférico, não-especificado & 20 & 4,1 \\
Leucemia/linfoma de célula T do adulto & 6 & 1,4 \\
Linfoma anaplásico de grandes células, CD30+ (célula T e nulo) & 6 & 2 \\
Inclassificáveis & & \\
\hline
\end{tabular}

\begin{tabular}{lc} 
& $\begin{array}{l}\text { Linfoma misto difuso - Working } \\
\text { Tabela } 4\end{array}$ \\
Formulation - 23 casos & \\
\hline Kiel & Número \\
Linfoepitelióide & 1 \\
Zona T & 2 \\
Pleomórfico de pequenas células & 2 \\
Linfoplasmocitóide & 2 \\
Pleomórfico de médias e grandes células & 16 \\
Real & \\
Linfoplasmocitóide & 2 \\
T periférico & 16 \\
Leucemia/linfoma de célula T do adulto & 5 \\
\hline
\end{tabular}

nor. Uma outra questão controversa da Working Formulation é a inclusão dos linfomas difusos de grandes células nos de grau intermediário. Estudos posteriores observaram que estas neoplasias apresentavam um pior prognóstico e deveriam ser classificadas como de alto grau de malignidade $(15,36,38)$. A prática tem demonstrado que o estudo imunoistoquímico é fundamental para classificar corretamente os LNH como entidades clinicopatológicas. Entretanto os patologistas aprende-
Linfoma de grandes células Tabela 5 Working Formulation - 52 casos

\begin{tabular}{lc} 
Kiel & Número \\
Centroblástico & 46 \\
Anaplásico de grandes células & 6 \\
Real & \\
Grandes células & 42 \\
Grandes células com esclerose do mediastino & 4 \\
Anaplásico de grandes células & 6 \\
\hline
\end{tabular}

Linfoma difuso de pequenas células Tabela 6 - Working Formulation - 13 casos

\begin{tabular}{lc} 
Kiel & Número \\
Monocitóide & 2 \\
Zona do manto & 8 \\
Pleomórfico de pequenas células & 3 \\
Real & \\
Zona do manto & 8 \\
Monocitóide & 2 \\
T periférico & 3 \\
\hline
\end{tabular}


ram muito com os estudos imunológicos e são capazes, através de marcadores morfológicos, de prever o fenótipo dos LNH em percentual significativo. Lennert e Feller (18) descreveram que é possível, em mãos de patologistas experientes, o diagnóstico de $85 \%$ a $90 \%$ dos casos somente pela morfologia. Em nosso material, foi possível determinar o fenótipo pelos aspectos morfológicos em $89,4 \%$. O estudo imunoistoquímico foi fundamental para estabelecer a linhagem linfóide em dois casos e para estabelecer o diagnóstico diferencial entre LNH e doença de Hodgkin em outros dois.

A avaliação imunoistoquímica feita neste estudo, com os anticorpos anti-CD20, anti-CD45RO, anti-CD45 e antiCD30, permitiu estabelecer o fenótipo na maior parte dos casos de LNH. Linder (20), Kurtin e Roche (16) acreditam que, com um anticorpo pan-B, como o CD20, altamente sensível e específico, associado a um anticorpo para linfócito $T$, tal como o CD45RO, muito sensível, é possível estabelecer o diagnóstico em $95 \%$ dos casos de linfomas T. Já outros autores recomendam a utilização de um painel com mais de um anticorpo $\mathrm{T}(2,18,31$, 42). Chadburn e Knowles (4) demonstraram que o CD20 reage com 95\% dos linfomas B, e não com os linfomas $T$, e o CD3 policlonal foi positivo em $95 \%$ dos linfomas T e negativo nos linfomas $B$. Outros autores mostraram que a positividade do CD20 em LNH B variou entre $96,6 \%$ (21) e $99 \%$ (3). Em nosso trabalho, empregamos o CD45 (LCA) quando houve necessidade de fazer o diagnóstico diferencial com outra neoplasia não-linfóide, e o CD30 para o diagnóstico dos linfomas anaplásicos de grandes células (Figuras 3 e 4).

Em nosso material, houve predomínio do fenótipo B, com 107 (74\%) casos. Proporções semelhantes (78\% e $80 \%$ ) foram encontradas, respectivamente, por Lennert

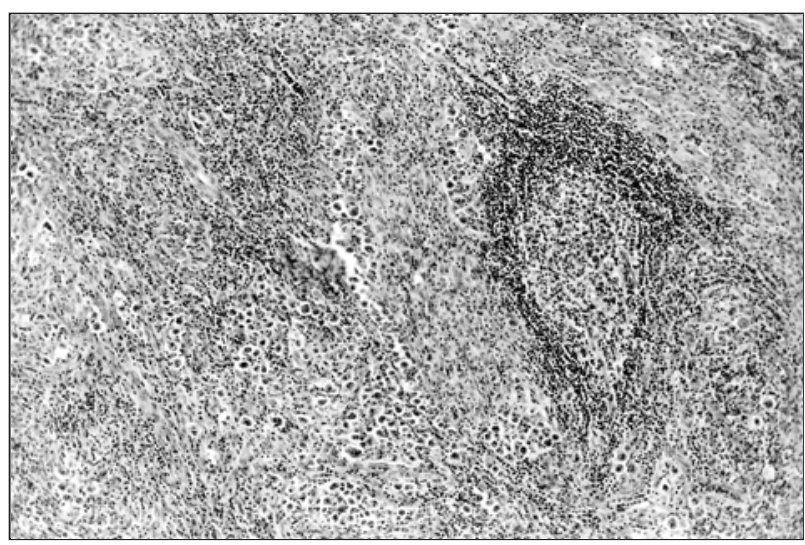

Figura 3 - Linfoma anaplásico de grandes células: ocupação do seio ganglionar por células grandes e pleomórficas

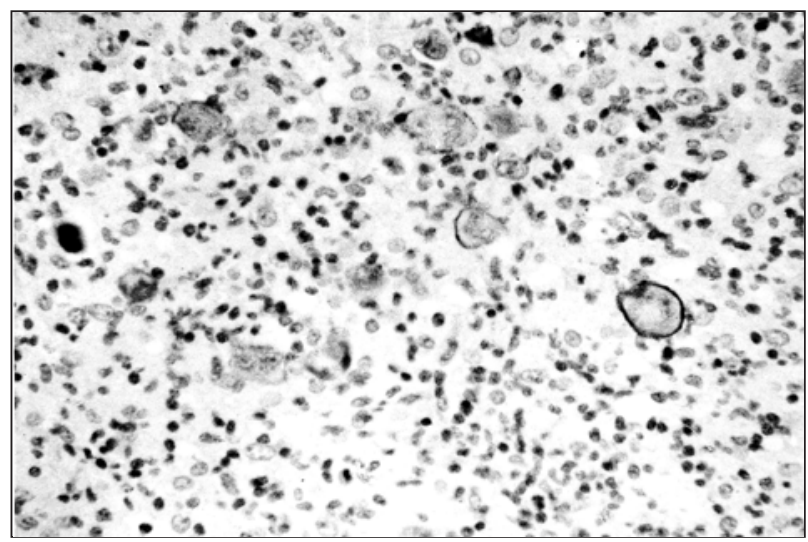

Figura 4 - Linfoma anaplásico de grandes células: imunopositividade de membrana celular com o anticorpo anti-CD30

(18) e por Lieberman et al. (19), e 88\% pelo International Lymphoma Study Group (30). Já os nossos linfomas T corresponderam a 22,7\%, com 33 casos. Os achados de literatura mostram uma variação entre $15 \%$ e $30 \%$ (9, 18 , 28, 42), com exceção de regiões como o Japão, o Caribe e a África, onde há alta incidência de linfomas T, em parte devido à infecção pelo retrovírus HTLV-I (11, 14, 24, 37). Em nossa experiência, devido a uma incidência significativa desta retrovirose em nosso meio, não podemos perder de vista o papel da suspeição da infecção pelo HTLV-I pelo patologista. Em $30 \%$ de nossos casos de LLTA, publicados recentemente (26), o diagnóstico foi sugerido pelos achados histopatológicos, em virtude do quadro de LNH com intenso pleomorfismo celular (26).

Em nossa casuística, os linfomas foliculares tiveram uma incidência de $20 \%$, com 29 casos. Incidência idêntica (20\%) foi encontrada na Europa por Lennert (18) (1992), e semelhante (22\%) pelo Non-Hodgkin's Lymphoma Classification Project (NHLCP) (30). Mais do dobro tem sido observado nos Estados Unidos, tornando-se um subgrupo muito importante neste país, principalmente devido ao seu curso indolente e a uma sobrevida maior $(7,41)$. Quando subdivididos, observamos oito casos $(5,5 \%)$ com predomínio de pequenas células (WF) ou grau I (Real), 12 (8,3\%), linfomas mistos (WF) ou grau II (Real), e nove $(6,2 \%)$ linfomas de grandes células (WF) ou grau III (Real). O subtipo mais comum entre os linfomas foliculares é o de pequenas células (Figura 5), correspondendo a $40 \%$ a $50 \%$ dos casos e apresentando um curso mais indolente $(12,35,40)$. Entretanto, em nosso estudo, encontramos predomínio do linfoma misto (41\%), seguido pelo de grandes células $(31, \%)$ e, por último, o de pequenas células (27\%). Especula-se que, em nossa 
população, o diagnóstico tardio poderia estar associado à apresentação com tipos histológicos mais agressivos, devido à progressão clonal.

Em nossos 33 casos diagnosticados, utilizando critérios morfológicos e imunoistoquímicos, observamos que o pleomorfismo celular foi um achado muito importante na suspeição morfológica dos LNH T (Figura 6). A proliferação vascular, a presença de um fundo inflamatório reativo constituído por eosinófilos, plasmócitos e histiócitos, por vezes formando granulomas epitelióides, foram achados constantes, entretanto não tão freqüentes quanto à irregularidade celular. Embora tenhamos conseguido aplicar a classificação de Kiel aos linfomas T, observamos que seu emprego é difícil pela extrema heterogeneidade. Concordamos em que não há um esquema ideal para classificação destas neoplasias $(6,32$, 42), apesar de existirem entidades bem definidas e já consagradas, tais como o linfoma angioimunoblástico, a micose fungóide e a LLTA.

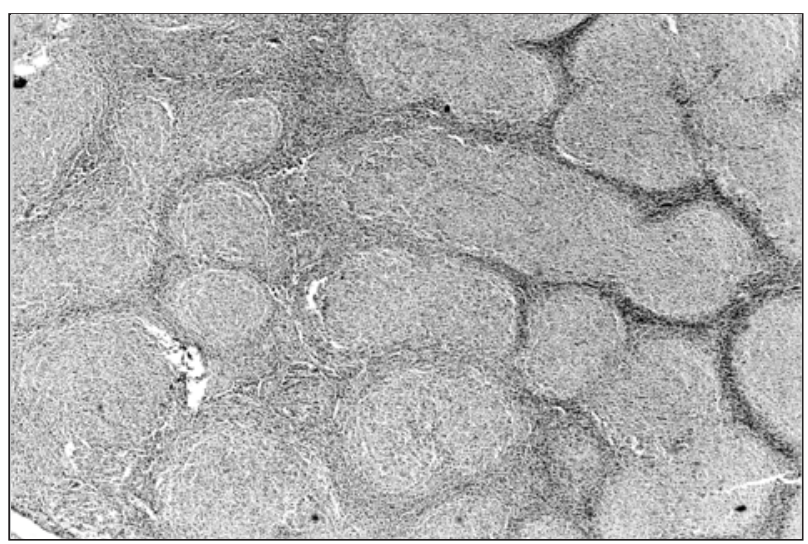

Figura 5 - Linfoma folicular de pequenas células (grau l): folículos linfóides justapostos com zona do manto escassa ou ausente

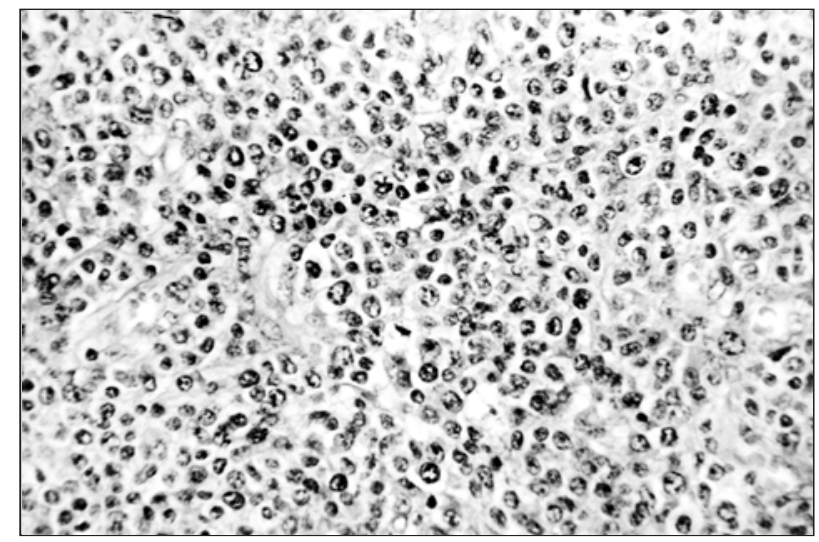

Figura 6 - Linfoma T periférico: linfócitos pleomórficos de tamanho pequeno, médio e grande associados a proliferação de vasos sangüíneos
Os linfomas de grandes células, na classificação de Kiel, são subdivididos em centroblástico e imunoblástico. Alguns trabalhos apóiam esta subdivisão devido ao pior prognóstico apresentado pelo linfoma imunoblástico (18, $25,35)$. Outros estudos demonstram que esta subdivisão é arbitrária, e os dois tipos morfológicos apresentam-se como linfomas de alto grau e, como tais, devem ser tratados agressivamente $(5,9,15,19,38)$. Pela classificação Real os subtipos de linfoma de grandes células foram englobados em uma só entidade, linfoma B difuso de grandes células (Figura 7). Entre os linfomas de grandes células, o único que mereceu uma classificação à parte foi o linfoma primário com esclerose do mediastino. Em nossa experiência, este linfoma, originado das células B intra-tímicas, apresenta-se como uma entidade anatomoclínica bem definida (8).

Em nossa casuística, quando dividimos os $\mathrm{LNH}$ em baixo e alto graus, de acordo com a classificação de Kiel modificada, observamos 57 casos (39\%) de linfomas de baixo grau e 86 (59\%) de linfomas de alto grau. Entre os linfomas de baixo grau em B e T, havia 49 casos $(33,8 \%)$ de linfomas B e oito $(5,5 \%)$ de linfomas $\mathrm{T}$. Em relação aos linfomas de alto grau, observamos 56 casos (38,6\%) de linfomas B e 26 $(17,9 \%)$ de linfomas T. Nossos achados diferem do grupo de Lennert (18), pois os $\mathrm{LNH}$ que predominaram foram os de alto grau, ao contrário do que foi descrito por este autor, que observou predominância dos LNH de baixo grau (63\%) em uma série de 1.220 pacientes.

A terceira classificação por nós utilizada foi a Real, que consiste em uma listagem de entidades clinicopatológicas reconhecidas e definidas por achados morfológicos, clínicos, imunofenotípicos e genotípicos. Esta proposta é mui-

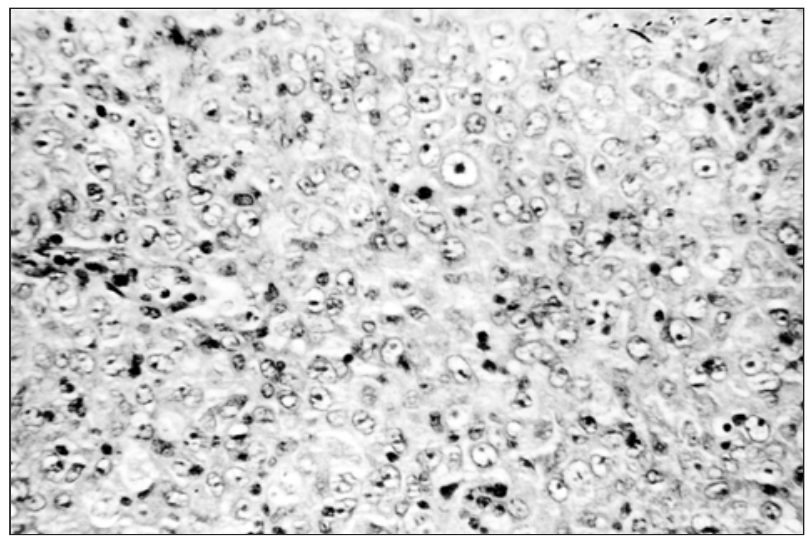

Figura 7 - Linfoma difuso de grandes células: proliferação difusa de células grandes com nucléolos ora únicos e centrais, ora múltiplos e periféricos 
to diferente da classificação da Working Formulation; entretanto assemelha-se à de Kiel modificada. Tanto a classificação de Kiel quanto a Real dividem os linfomas formados por células B e T, definem entidades biológicas e relacionam as células neoplásicas, sempre que possível, com as células de origem (9).

Na classificação Real, os linfomas não são divididos em graus de malignidade, como nas duas classificações discutidas anteriormente, pois os autores acreditam que muitas destas neoplasias, como a leucemia linfóide crônica/linfoma linfocítico, o linfoma de células do centro do folículo, o linfoma da zona do manto e a leucemia/linfoma de células $T$ do adulto apresentam comportamento clínico que transita entre o indolente e o agressivo $(5,9)$. A classificação Real representa, segundo Jaffe (13) um novo paradigma na classificação dos linfomas. A inclusão de critérios clínicos entre os fatores de definição destas entidades veio proporcionar uma nova dimensão à análise diagnóstica.

No estudo feito pelo International Lymphoma Study Group (30) (NHLCP 1997) com 1.403 casos de LNH, utilizando os fatores prognósticos definidos pelo Índice Prognóstico Internacional (IPI), conclui-se que o diagnóstico histológico de um tipo específico de LNH tem importância, mas deve estar associado ao IPI para uma melhor decisão clínica. Foi observado que pacientes com LNH de baixo grau histológico e alto risco prognóstico apresentaram sobrevida menor, enquanto pacientes com LNH de alto grau histológico e com baixo risco prognóstico tiveram melhor sobrevida.

Algumas entidades consideradas provisórias na classificação Real foram analisadas em nosso material. $\mathrm{O}$ linfoma anaplásico de grandes células (LAGC), do tipo Hodgkin, não foi observado em nossos seis casos, pois tratavam-se de formas clássicas. A subclassificação dos linfomas $T$ foi feita de acordo com a classificação de Kiel modificada. Entretanto estas neoplasias são de difícil caracterização, devido à sua menor incidência, à sua heterogeneidade e à dificuldade em determinar a célula normal de origem (6). Portanto a simplificação sugerida pela Real de agrupar em uma só entidade os linfomas $T$ periféricos foi extremamente bem-vinda; os subtipos ficaram em categorias provisórias.

Em nossa série, houve predomínio dos linfomas de grandes células (WF), com 52 casos (35,9\%); centroblásticos (Kiel), com 46 casos (31,7\%); e linfomas de grandes células B (Real), com 43 casos $(29,7 \%)$. Estes linfomas, em alguns estudos, são os que predominam com uma incidência de $30 \%$ a $40 \%$ dos $\operatorname{LNH}(9,19,30)$. Na série do National Cancer Institute (35), eles corresponderam a 19,7\% e, na de Lennert e Feller (18), a 13,7\%.

Em recente artigo, publicado pelo mesmo grupo (30), 1.403 casos de diferentes partes do mundo foram analisados e classificados de acordo com a Real. O linfoma difuso de grandes células B apresentou maior incidência (31\%), seguido pelo linfoma folicular $(22,1 \%)$. Os linfomas $T$ corresponderam a apenas $12 \%$. Este estudo mostrou ser possível aplicar esta classificação, utilizando-se as definições propostas pelo grupo, identificando entidades clinicamente distintas.

Recentemente foi publicada a Classificação Real Revisitada sob os auspícios da OMS. Este projeto envolveu patologistas, clínicos e oncologistas numa tentativa de chegar a um consenso e, se possível, após décadas de controvérsia, ter uma classificação única com aceitação universal $(10,13)$.

As principais modificações propostas da OMS em relação à Real foram: considerar o linfoma linfoblástico e a leucemia linfoblástica a mesma doença com apresentações clínicas diferentes; incluir as anormalidades citogenéticas quando estas influenciarem o prognóstico; mudar a nomenclatura de linfoma de células do centro do folículo para linfoma folicular; graduar os linfomas foliculares levando em conta o número de células grandes, conforme proposição de Mann e Berard (23), e pelas áreas difusas de acordo com a proposta da Real; utilizar o termo linfoma Malt somente para os casos compostos, predominantemente, por células pequenas; para os casos denominados de linfoma Malt de alto grau usar a terminologia de linfoma de grandes células; considerar os linfomas de zona marginal nodal e esplênico entidades distintas $(10,13)$.

Em resumo, nossos dados evidenciaram que a classificação de Kiel modificada e a Real devem ser as preferidas, pois empregam, além da análise morfológica, um estudo imunológico que define entidades biológicas, correlacionando-as, quando possível, com a célula de origem. Contudo a Real vai além; ao incluir o critério clínico e salientar o local de apresentação, cria importantes indícios para a distinção biológica e para a definição das entidades. Na verdade, a Real representa um novo paradigma na classificação dos linfomas (13). Esta tem sido a nossa prática, de correlacionar os dados clínicos com os morfológicos. Além disto, o estudo imunoistoquímico tem sido fundamental para classificar corretamente os linfomas. 


\section{Referências}

I. Burke, J.S. The histopathologic classification of non-Hodgkin's lymphomas: ambiguities in the Working Formulation and two newly reported categories. Seminars in Oncology, 17 : 3-10, 1990.

2. Cabeçadas, J.M. \& Isaacson, P.G. Phenotyping of T-cell lymphomas in paraffin sections - which antibodies? Histopathology, 19 : 4|9-24, 1991.

3. Cartun, R.W. et al. Utilization of monoclonal antibody L26 in the identification and confirmation of B-cell lymphomas. A sensitive and specific marker applicable to formalin-and B5-fixed, paraffin-embedded tissues. Am.J. Pathol., 129:4I 5$21,1987$.

4. Chadburn, A. \& Knowles, D.M. Paraffin resistant antigens detectable by antibodies $\mathrm{L} 26$ and $C D 3$ predict the B or T cell lineage of $97 \%$ of diffuse aggressive non-Hodgkin's lymphoma. Lab. Invest., 68: 87 A, 1993.

5. Chan, J.K.C. et al. A revised European-American classification of lymphoid neoplasm proposed by the International Lymphoma Study Group. A summary version. Am. J. Clin. Pathol., 5: 543-60, 1994.

6. Chan, J.K.C. PeripheralT-cell and NK-cell neoplasm. In: Long course in hematopathology. Boston: USCAP, 1998.

7. Denham, J.W. et al. The follicular non-Hodgkin's lymphomas. II.Prognostic factors: What do they mean? European J. Cancer, 32: 480-90, 1996.

8. Franco, S. et al. Linfoma de grandes células com esclerose do mediastino (Mediastinal large cell lymphoma with sclerosis). J. Bras. Patol., 3 I: 46-54, 1995.

9. Harris, N.L. et al. A revised European-American classification of lymphoid neoplasm: a proposal from the international lymphoma study group. Blood, 84: 1 361-92, 1994.

10. Harris, N.L. et al. The World Health Organization classification of neoplastic diseases of the haematopoietic and lymphoid tissues: report of the Clinical Advisory Committee Meeting, Arlie House, Virginia, November 1997. Histopathology, 36: 69-87, 2000.

I I. Hinuma, Y. et al. Antibodies to adult T-cell leukemia-virusassociated antigen (ATLA) in sera from patients with ATL and controls in Japan: a nation-wide sero-epidemiologic study. Int. J. Cancer, 29: 631-5, 1982.

12. Jaffe, E.S. Surgical pathology of the lymph nodes and related organs. 2. ed. Philadelphia, London, Toronto, Montreal, Sydney, Tokyo:W. B. Saunders Company, 1995, 659p.

13. Jaffe, E.S. Introduction to the WHO classification. Am. J. Surg. Pathol., 2 I (I): I |4-121, 1997.

I 4. Kim, J.H. \& Durack, D.T. Manifestations of human T-lymphotropic virus type I infection. Am. J. Med., 84:919-28, 1988.

15. Krueger, G.R.F. et al. A new Working Formulation of nonHodgkin's lymphomas. A retrospective study of the new $\mathrm{NCl}$ classification proposal in comparison to the Rappaport and Kiel classifications. Cancer, 52:833-40, 1983.

16. Kurtin, P.J. \& Roche, P.C. Immunoperoxidase staining of nonHodgkin's lymphomas for T-cell lineage associated antigens in paraffin sections. Am.J. Surg. Pathol., I 7(9): 898-904, 1993.
17. Lennert, K. et al. Classification of non-Hodgkin's lymphomas. Lancet, II: 406-8, 1974.

18. Lennert, K. \& Feller, A. Histopathology of non-Hodgkin's lymphomas (based on the updated Kiel classification). Berlin, Heidelberg, New York: Springer-Verlag, 1992, 312p.

19. Lieberman, P.H. et al. Evaluation of malignant lymphomas using three classifications and the Working Formulation. Am. J. Medicine., 81:365-79, 1986.

20. Linder, J. Antibodies marking paraffin-embedded leukocytes. Status report 1991. Am. J. Clin. Pathol., 95:607-8, 1991.

21. Linder, J. et al. Monoclonal antibodies marking B-cell nonHodgkin's lymphoma in paraffin-embedded tissue. Mod. Pathol., I: 29-34, 1988.

22. Lukes, R.J. \& Collins, R.D. Immunologic characterization of human malignant lymphomas. Cancer, 34: 1488-503, 1974.

23. Mann, R.B. \& Berard, C.W. Criteria for the cytologic subclassification of follicular lymphomas: a proposed alternative method. Hematol. Oncol., I: I87-92, 1983.

24. Manns, A. et al. Role of HTLV-I in development of nonHodgkin lymphoma in Jamaica and Trinidad e Tobago. Lancet, 342: 1447-50, 1993.

25. Meusers, P. et al. Why not adhere to the original Kiel classification? Lancet, 2: I 194, 1980.

26. Milito, C.B. et al. Leucemia/linfoma de células $T$ do adulto no Rio de Janeiro: estudo clinicopatológico de dez casos. J. Bras. Patol., 36: 45-53, 2000.

27. Montalban, $C$. et al. Peripheral T-cell lymphoma: a clinicopathological study of $4 \mathrm{I}$ cases and evaluation of the prognostic significance of the updated Kiel classification. Histopathology, 22: 303-10, 1993.

28. Nakamura, S. et al. Clinicopathologic study of 212 cases of peripheral T-cell lymphoma among the Japanese. Cancer, 72: 1762-72, 1993.

29. NCI Non-Hodgkin's Classification Project Writing Commitee. Classification of non-Hodgkin's lymphomas. Reproducibility of major classification systems. Cancer, 55: 91-95, 1985.

30. Non-Hodgkin's Lymphoma Classification Project. A clinical evaluation of the International Lymphoma Study Group Classification of Non-Hodgkin's Lymphoma. Blood, 89: 3909-18, 1997.

31. Perkins, S.L. \& Kjeldsberg, C.R. Immunophenotyping of lymphomas and leukemias in paraffin-embedded tissues. Am. J. Clin. Pathol., 99: 362-73, 1992.

32. Pinkus, G.S. et al. Peripheral/post-thymic T-cell lymphomas:A spectrum of disease. Clinical, pathologic and immunologic features of 78 cases. Cancer, 65: 97।-98, 1990.

33. Rappaport, H. Tumors of the hematopoietic system. Washington, DC: Armed Forces Institute of Pathology, 1966, 442p.

34. Rappaport, $H$. Roundtable discussion of histopathologic classification. Cancer Treat. Rep., 61: 1037-48, 1977.

35. Rosenberg, S.A. et al. National Cancer Institute sponsored study of classifications of non-Hodgkin's lymphomas. Summary and descriptions of a Working Formulation for clinical usage. Cancer, 49: 21 12-35, 1982. 
36. Rudders, R.A. et al.Adult non-Hodgkin's lymphoma. Correlation of cell surface marker phenotype with prognosis, the new Working Formulation, and the Rappaport and the LukesCollins histomorphologic schemes. Cancer, 52: 2289-99, 1983.

37. Saxinger, W. et al. Human T-cell leukemia virus (HTLV-I) antibodies in Africa. Science, 225: | 473-6, 1984.

38. Simon, R. et al. The non-Hodgkin's lymphoma pathologic classification project. Long-term follow-up of I, I 53 patients with non-Hodgkin's lymphomas. Ann Intern Medicine, 109: 939-45, 1988.
39. Stansfeld, A. G. et al. Updated Kiel classification for lymphomas. Lancet, I: 292-3, 1988.

40. Warnke, R.A. et al. Atlas of tumor pathology. Tumors of the lymph nodes and spleen. Bethesda,Mayland: Armed Forces Institute of Pathology. 1995, 544p.

4I.Weisenburger, D.D. \& Chan,W.C. Lymphomas of follicles. Mantle cell and follicle center lymphomas. Am J Clin Pathol, 99:409. 20, 1992.

42. Winberg, C.D. Peripheral T-cell lymphoma. Morphologic and immunologic observations. Am J Clin Pathol, 99: 426-35, 1993. 